\title{
Türk Dünyası Kültür Başkentleri, Ed. Fırat Yaldız, Ankara: Nobel Yayınları 2020, 504 Sayfa, ISBN: 978-625-402-264-7
}

\section{Mustafa ERTÜRK ${ }^{1}$ ()}

Sorumlu yazar/Corresponding author:

Mustafa Ertürk (Dr.)

E-posta: ORCID: 0000-0001-7172-7133

Başvuru/Submitted: 20.03.2020 • Revizyon Talebi/Revision Requested: 05.04.2020 • Son Revizyon/Last Revision Received: 05.05.2020 • Kabul/Accepted: 25.05 .2020 • Online Yayın/Published Online: 18.06.2020

Kent ve kültür arasındaki ilişki kentin ve kültürün farklı düzeylerde seyreden sosyolojik, politik, tarihsel ve ekonomik alanlarının birbirlerini belirlemesine kaynaklık edebilecek kadar sı1kı örülmüş bir dokuya işaret eder. Bir yandan kent, kültürün yaşam alanını oluştururken aynı anda kültür, kenti sürekli üreterek kendisi için yaşam alanı olan kentin tüm düzeylerde formunu ve muhtevasını yapılandırır.

Yirminci yüzyılın son çeyreğinde kent ve kültür arasındaki bu ilişkinin evreni yerel olandan küresel olana doğru hızlı bir kaymaya tanıklık etmektedir. Bu tanıklığın zemini ise "Kültür Başkentleri” sürecinde somutlaşmaktadır. "Kültür Başkentleri” kavramı kültür ve kent kavramlarının söz konusu ilişkisinden çok daha fazlasına işaret etmek amacıyla oluşturulmuştur. Bu fazlalık, kültür ve kent kavramlarının yerel tonlu sosyolojik ve antropolojik bağlamlarını da tanımda saklı tutarak yerelin ötesinde bölgesel anlamda ortak olanın farkındalığına gönderme yapmakta ve kültür ve kente ait kimliklerin ortak unsurlarına bölgeselde ulaşma çabasına işaret etmektedir. Bir başka ifadeyle yerelin bölgesel ve küresel alanda kendinden olanı ve/veya kendisini araması ve bu arayış sürecinde kendisini mekân ve bilinç düzleminde eş zamanlı olarak genişletmek ve pekiştirmek amacına matuf olan ortak kültürel bilincin pekiştirilmesine hizmet etmektedir. Bu pekiştirmenin günümüzde zemini 
olan alanların başında şüphesiz biri sosyolojinin, diğeri siyaset bilimi ve uluslararası ilişkilere ait iki kavramın (kültür ve başkent) terkibinden oluşturulan Kültür Başkentleri gelmektedir.

Kültür Başkentleri, kültür ve kültürel ürünlerin birleştirici gücünü kentler üzerinden pratiğe kavuşturmak amacıyla Yunanistan'ın eski Kültür Bakanı Melina Mercouri tarafından 1985 yılında “Avrupa Kültür Başkentleri” markası adı altında başlatılmış bir süreçtir. Avrupa Kültür Başkentleri süreci, söz konusu tarihten bu yana kentlerin kültürel, sosyal ve ekonomik alandaki gelişmelerine katkı sağlamıştır. Bununla birlikte Avrupa Kültür Başkentleri sürecinin yerel ile bölgesel olanı mecz ederek ortak kültür mirası zemininde yükselen Avrupalılık kimliğinin kültür ve kent ekseninde pekiştirilmesine yönelik başarısı tartışmalıdır.

İki kutuplu dünyanın yirminci yüzyılın başlarında ortadan kalkması ile bölgesel ittifakların önemi artmıştır. Bu bağlamda bölgesel ittifakların farklı alanlarda gerçekleştirilmesine yönelik arayışlardan birine işaret eden Kültür Başkentleri uygulaması tüm dünyada kısa zamanda hızla yayılmıştır. Avrupa Kültür Başkentleri uygulamasını İslam Kültür Başkentleri, Amerika Kültür Başkentleri, Güneydoğu Asya Kültür Başkentleri, Bağımsız Devletler Topluluğu Kültür Başkentleri ve Doğu Asya Kültür Kentleri gibi Kültür Başkentleri uygulamalarının takip ettiği görülmektedir. Dünyanın farklı bölgelerinde Kültür Başkenti uygulamalarının bu denli hızlı yayılması, siyasal ve toplumsal alanda ortak kültür, iş birliği ve kültürel kimliğin oluşturulması anlamında kullanışlı bir süreç ve enstrümana dönüştüğünün göstergesi olarak görülebilir.

Kültür Başkentliği uygulamasının, kültürel uyum ve iş birliği açısından tüm dünyada yaygınlaşması sürecine Uluslararası Türk Kültürü Teşkilatı'nın (TÜRKSOY) çabalarıyla Türk Dünyası da dâhil olmuştur. 1992 yılında başlayan Türk Dili Konuşan Ülkeler Devlet Başkanları Zirveleri'nde şekillenen fikirlerin bir yansıması olarak Türk Dünyası Kültür Başkentleri uygulaması 2010 yılında TÜRKSOY'un girişimi ile hayata geçirilmiş ve ilk kez 2012 yılında Türk Dili Konuşan Ülkeler Kültür Bakanları Daimî Konseyi’nin oy birliği ile Kazakistan’ın Astana şehrine ilk “Türk Dünyası Kültür Başkenti” unvanı verilerek süreç başlamıştır. 2012 yılından beri TÜRKSOY tarafından sürdürülen Türk Dünyası Kültür Başkentleri uygulaması kesintisiz olarak devam etmektedir. Dokuz yıldır devam eden Türk Dünyası Kültür Başkentleri uygulaması Türk Dünyası'nın ortak değerlerinin araştırılması, geliştirilmesi, tanıtılması ve kültürel bağların sürdürülmesi misyonunu taşımakla beraber Türk devletleri arasındaki uluslararası ilişkiler düzleminde bir iş birliği ve Türk toplulukları arasındaki kültürel etkileşimden daha öteye bir anlam ve pratiği hedefleyerek kendisinden önceki örneklere benzer şekilde Türk dünyasına ilişkin kültür ve kent zemininde "ortak bir miras" üzerinden "ortak bir kimliğe" de gönderme yapmaktadır.

Önemli ve dikkate değer bir misyon yüküyle ortaya çıkan ve günümüze kadar her yıl düzenli olarak gerçekleşmekte olan Türk Dünyası Kültür Başkentleri uygulamalarına ilişkin farklı boyutları derli toplu bir biçimde ele almayı amaçlayan Fırat Yaldız editörlüğünde hazırlanan Türk Dünyası Kültür Başkentleri adlı çalışma, Kültür Başkentleri kavramını, 
kavramsal ve kuramsal çerçevesini, Türk Dünyası Kültür Başkentleri uygulamasının ortaya çıkış sürecini ve günümüze kadar Türk Dünyası Kültür Başkenti olarak seçilen 9 Kültür Başkentini detaylı bir biçimde konu edinmektedir.

$\mathrm{Bu}$ açıdan, Türk Dünyası Kültür Başkentleri genel anlamda Kültür Başkentleri konusunda Türkçede ilk kuramsal kaynak olmasının yanı sıra, 2012 yılından bu yana seçilen Türk Dünyası Kültür Başkentlerinin her birini ayrı başlık altında ve detaylı bir biçimde ele alması nedeniyle uygulama örneklerine ilişkin de ilk eser özelliğini taşımaktadır. Çalışma, aynı zamanda günümüze kadar Türk Dünyası Kültür Başkenti olarak seçilen kentlerin Kültür Başkentliği sürecine ilişkin ayrıntılı bir tarihî arşiv olmakla birlikte ortaya çıkan deneyimlerden hareketle gelecekteki Kültür Başkentleri uygulamaları için de bünyesinde teklifler barındıran bir projeksiyon ve rehber olma niteliğindedir.

Kitabın editörü Yaldız yazdığg 1 Ön Söz ${ }^{1}$ de 2012 yılından beri devam etmekte olan ve Türk Dünyası Kültür Başkentleri ile ilgili bilimsel nitelikli bir eseri hazırlamanın gerekliliğinden hareketle çalışmayı, farklı disiplinlerden gelen akademisyenler tarafından kaleme alınan ve Türk Dünyası Kültür Başkentleri'ne dair ilk akademik çalışma olarak takdim etmektedir. TÜRKSOY Genel Sekreteri Dusen Kaseinov ise kaleme aldığı Sunuş ${ }^{2}$ ta, eseri, Türk dünyasının ortak kültürünün üzerinde yükselen şehirlerin, Türk dünyasının ortak hafızası olduğu ve bu hafizanın kalıcı bir biçimde korunarak gelecek nesillere aktarılabilmesine olanak sağlamak amacıyla hazırlanan ilk çalışma olarak sunmaktadır. Dolayısıyla kitap, Türk Dünyası Kültür Başkentlerine ilişkin ilk akademik çalışma ve geleceğe yönelik bir misyon taşıyan ilk tarihsel kayıt örneğidir. Kitabın Giriş ${ }^{3}$ bölümünü kaleme alan Orhan Kavuncu, Sovyetler Birliğinin dağılmasıyla Türk dünyası içindeki ilişkilerin yeni bir döneme doğru seyretmesinde temel kurumsal aktörlerin önemini 1990 sonrası iki kutuplu dünyanın ortadan kalkması ile uluslararası ilişkilerde bölgesel kimliklerin kazandığı bölgesel entegrasyon politikalarına evrilen yeni kültürel boyut bağlamında ele alarak yeni durumun Türk Dünyası adına bir firsat olabileceğine dikkat çekmektedir.

Fırat Purtaş, TÜRKSOY ve Türk Dünyası Kültür Başkentleri ${ }^{4}$ başlıklı bölümde, Türk Dünyası Kültür Başkentliğinin yaklaşık otuz yıla dayanan uzun tarihsel sürecini, Türk dünyasının çeşitli düzeylerde aktörlerinin yoğun çabaları etrafında ayrıntılı bir biçimde okuyucuya sunmaktadır. Purtaş, bir anlamda Kültür Başkentliği sürecinin Türk Cumhuriyetleri arasındaki kültürel ortaklığın güçlendirilmesi ve çok yönlü uyumun derinleştirilmesi bağlamında Türk devlet ve toplulukları arasındaki sürdürülebilir iş birliğinin bir sembolüne nasıl dönüştügünün serencamını ortaya koymaktadır. Yazar, bir şehrin Türk Dünyası Kültür

1 Fırat Yaldız, Türk Dünyası Kültür Başkentleri adlı kitabına Ön Söz (Ankara: Nobel Yayınları, 2020), V.

2 Dusen Kaseinov, Türk Dünyası Kültür Başkentleri adlı kitabına Sunuş (Ankara: Nobel Yayınları, 2020), VIIIX.

3 Orhan Kavuncu, Türk Dünyası Kültür Başkentleri adlı kitabına Giriş (Ankara: Nobel Yayınları, 2020), XIXXV.

4 Fırat Purtaş, “TÜRKSOY ve Türk Dünyası Kültür Başkentleri”, Türk Dünyası Kültür Başkentler içinde, (Ankara: Nobel Yayınları, 2020), 1-16. 
Başkenti ilan edilmesi için nasıl bir süreçten geçtiği, Dünyanın farklı bölgelerindeki Kültür Başkentliği uygulamaları ile karşılaştırıldığında Türk Dünyası Kültür Başkentlerinin hangi ölçüde etkili olduğu, Türk Dünyası Kültür Başkenti olarak seçilen Kültür Başkentliğinin sağladığı fayda, Türk devlet ve toplulukları arasındaki kültürel ortaklığa sunduğu katk1 gibi sorulara verdiği yanıtlar bağlamında Türk Dünyası Kültür Başkenti uygulamasının Türk dünyasının bütünleşmesi, çok yönlü iş birliği ve ortaklık çabalarına yeni bir sinerji oluşturduğu sonucuna ulaşmaktadır.

Eserin kavramsal çerçevesinin bir bölümü olarak Ayşe Çolpan Yaldız, tarafından kaleme alınan Kültür Başkenti Uygulamaları: Kavramsal ve Kuramsal Arka Plan ${ }^{5}$ başlıklı bölüm, Kültür Başkenti kavram ve kuramını coğrafya, kent ve kimlik konularının ve ilişkisinin uluslararası ilişkilerde son dönemde kazandıkları önem üzerinden temellendirmektedir. Yazar, Kültür Başkentlerinin ortaya çıkış sürecini bölgeselcilik çalışmaları ve inşacılık perspektifine referansla kavramsallaştırmaktadır. Yaldız, bu kuramsal girişin ardından dünya uygulamalarını incelediği kısımda ise öncelikle, Kültür Başkentleri kavramının uluslararası ilişkilerde ortaya çıkmasıyla beraber, bu sürecin uluslararası ilişkiler, ulus devletler, bölgesel kurumlar ve kentler açısından sonuçları ve etkilerini ele alarak kavramsal çerçeve ile pratik süreç arasındaki köprüyü ustalıkla kurmaktadır. Son olarak yazar, başta Avrupa Kültür Başkentleri örneği olmak üzere dünyadaki farklı Kültür Başkenti deneyimlerinin ortaya çıkış süreçleri, Kültür Başkenti ilan edilen kentlere katkısı ve söz konusu bölgesel kimliğe katkılarını ele almaktadır. Yaldız, söz konusu deneyimleri analizinde Avrupa Kültür Başkentleri uygulamaları dışındaki uygulamaların maalesef kentlere ve ortak kültürel kimliğe kalıcı etkiler bırakacak niteliklerden yoksun olduğu ve yine Avrupa Kültür Başkentleri uygulaması dışındaki uygulamaların genellikle resmî kurumlarla sınırlı olduğu için bilgi ve verilere ulaşmada kısıtlıklar yaşanması nedeniyle inceleme ve değerlendirme sıkıntıları bulunduğuna yönelik iki önemli sonuca ulaşmaktadır. Ayşe Çolpan Yaldız'ın ulaştığı bu iki önemli sonuç, gelecekte seçilecek olan Türk Dünyası Kültür Başkentleri için bir öneri olarak değerlendirilmeyi hak etmektedir.

Türk Dünyası Kültür Başkentleri ve İletişim Stratejileri' ${ }^{6}$ başlıklı bölümde Türk Dünyası Kültür Başkentleri projesini şehirler ve kültürler açısından oldukça zengin, dünya çapında tanınırlık açısından ise bakir bir alan olarak tanımlayan Erkam Temir doğru iletişim yöntemlerinin uzun soluklu ve etkili bir biçimde planlaması koşuluyla Türk Dünyası Kültür Başkentleri projesinin önümüzdeki yıllarda dünya çapında bir projeye taşınabileceğine ilişkin potansiyeline dikkat çekmektedir. Yazar, bu çerçevede, Türk Dünyası Kültür Başkentlerinin bilhassa tüm dünyada görünürlüğünün arttırılması, şehirlerin ve kültürün bu yönüyle tanıtılmasında uygulanacak iletişim yöntemlerinin kapsam ve sınırlılıklarını

5 Ayșe Çolpan Yaldız, "Kültür Başkenti Uygulamaları: Kavramsal ve Kuramsal Arka Plan”, Türk Dünyası Kültür Başkentleri içinde, (Ankara: Nobel Yayınları, 2020), 17-47.

6 Erkam Temir, “Türk Dünyası Kültür Başkentleri ve İletişim Stratejileri”, Türk Dünyası Kültür Başkentleri içinde, (Ankara: Nobel Yayınları, 2020), 49-72. 
ekonomik maliyet, kâr ve zarar çerçevesi içine hapseden bir düşünceyi aşmanın gerekliliğine vurgu yapmaktadır. Günümüze kadar gerçekleştirilen Kültür Başkenti uygulamaları dikkate alınarak uygulamanın iletişim boyutuna vurgu yapılmak üzere daha sistematik ve profesyonel bir iletişim yaklaşımının gerekliliği sonucuna ulaşan yazar, örnekler üzerinden bir durum analizi yaptıktan sonra yürütülen mevcut iletişim çalışmalarına rağmen, Türk Dünyası Kültür Başkenti uygulamasını iletişim açısından yaşanan yetersizlikler nedeniyle "Türk Dünyası Kültür Başkentleri 2.0" olarak adlandırdığı bir sonraki evreye taşınmasının gerekliliğine işaret etmektedir.

Genelde Kültür Başkenti, özelde ise Türk Dünyası Kültür Başkentini kavram, kuram, kurum ve iletişim bağlamında ele alan ilk üç bölümün ardından eserin diğer bölümleri Türk Dünyası Kültür Başkentleri uygulama örneklerine ayrılmıştır. Dördüncü bölümden itibaren her bölümde Türk Dünyası Kültür Başkenti seçilen dokuz kentin(2012 Astana, 2013 Eskişehir, 2014 Kazan, 2015 Merv, 2016 Şeki, 2017 Türkistan, 2018 Kastamonu, 2019 Oş, 2020 Hive) her biri müstakil bir bölüm olarak farklı disiplinlerden gelen akademisyenler tarafindan kaleme alınmıştır. Uygulama örneklerinin ele alındığg bölümlerde ortak bir inceleme yöntemi takip edilerek kentin coğrafi konum ve tarihi, Türk Dünyası Kültür Başkenti seçilmeden önce ekonomik, toplumsal, siyasal ve kültürel yapısı, Kültür Başkenti seçilme süreci, Kültür Başkenti olarak gerçekleştirilen faaliyet ve organizasyonlar ve son olarak Kültür Başkenti seçildikten sonra ortaya çıkan toplumsal, ekonomik, siyasal ve kültürel değişimler açısından incelenmiş; bölüm sonuçlarında da her bir yazar, kentin Türk Dünyası Kültür Başkenti seçilmesinin kente katkısı ve Türk dünyası kimliğine etkilerine değinmiştir.

Bu çerçevede, 2012 yılında ilk Türk Dünyası Kültür Başkenti ilan edilen Kazakistan'ın başkenti Astana'nın ele alındığı 2012 Yılı Türk Dünyası Kültür Başkenti: Astana ${ }^{7}$ başlıklı bölümde, Ainur Nogayeva, çalışmada yer alan diğer Kültür Başkentlerinden farklı olarak Astana'nın, Türk Dünyası Kültür Başkenti seçilen tek resmî siyasal başkent konumunda olduğuna dikkat çekmektedir. Yazar, Kültür Başkentliği sürecinin siyasi karar alıcıların yoğun desteği ile yürütülmesinin Türk Dünyasına etkisini Türk Dünyasının kutsal kenti Türkistan'a rakip yeni bir kültür merkezinin öne çıkması olarak yorumlamaktadır. Yazar, aynı yıl -2012'de- Astana'nın, Bağımsız Devletler Topluluğu'nun da (BDT) Kültür Başkenti olarak seçilmesini Kazakistan’ın Avrasya entegrasyonundaki büyük rolünün ispatı olarak nitelendirmektedir. Astana'nın Türk Dünyası Kültür Başkenti seçilmesi ile Kazakistan'ın uluslararası arenada itibar güvenliğine yönelik olumlu sonuçlarının olduğu yorumuna ulaşan yazar, bu durumun Astana'nın bir markaya dönüşüm sürecine önemli derecede katkılar sunduğu görüşündedir.

7 Ainur Nogayeva, “2012 Y11ı Türk Dünyası Kültür Başkenti: Astana”, Türk Dünyası Kültür Başkentleri içinde, (Ankara: Nobel Yayınları, 2020), 73-126. 
2013 Yılı Türk Dünyası Kültür Başkenti: Eskişehir ${ }^{8}$ başlıklı bölümde Mehmet Topal, demografik özellikleri itibariyle Türk dünyasının adeta bir özeti olarak nitelendirdiği Eskişehir'in, tarihsel süreçteki toplumsal aktörler (muhacirler) ve siyasal yönetimlerin (Selçuklular, beylikler, Osmanlı ve Cumhuriyet dönemi) izlerinin bileşkesinde oluşan Eskişehirlilik bilinç ve kimliği ile Türk Dünyası Kültür Başkenti olarak seçilmesi arasındaki uyuma işaret etmektedir. Eskişehir'in Kültür Başkenti seçilmesi ile yazara göre, şehrin zaten var olan 'Kültür Şehri' kimliği yerel değerlerin öne çıkarılmasıyla anlam kazanmış ve bu sıfat pekişmiştir. Eskişehir'in 2013 Türk Dünyası Kültür Başkenti olması ile Türkiye'de Kültür Başkentliğine dair farkındalık oluşmaya başladığına işaret eden Topal, süreçte başarılı etkinlikler gerçekleştiren Eskişehir'in hem ulusal ve hem de uluslararası alanda imajının güçlendirilmiş, ziyaretçilerin şehre olan bakış açılarının olumlu yönde gelişimi sağlanmış olduğunu ve neticede marka bir şehir hâline geldiğini belirtmektedir. $\mathrm{Bu}$ markalaşma sürecinin başarısının arkasında yatan temel etken ise, Türkiye'de ilk defa bir şehrin Türk Dünyası Kültür Başkenti olması nedeniyle sürecin etkin bir biçimde değerlendirilmesi, şehrin bu düşünceye ve faaliyetlere 1sıtılması, etkinliklerin planlanması ve yönetilmesi, süreçte kamu ve sivil kurumların yapacakları çalışmalarda koordinasyonun sağlanması amacıyla -ve diğer Kültür Başkentlerinden farklı olarak-Eskişehir 2013 Türk Dünyası Kültür Başkenti Ajansı'nın kurulmuş olmasıdır.

Türk Dünyası Kültür Başkenti unvanını Eskişehir'den devralan Kazan'ın, diğer Kültür Başkentlerinden farklı olarak Rusya Federasyonu sınırları içerisinde bulunan bir özerk cumhuriyetin (Tataristan) başkenti olduğuna işaret eden Guzel Sadykova, 2014 Yılı

Türk Dünyası Kültür Başkenti Kazan' başlıklı bölümde, Kazan'1 çok kültürlü şehir kimliği, barış, uyum ve hoşgörü ilkelerinin önceliğine dayanan, birlikte yaşama ve gelişme felsefesini içselleştiren, küresel teknoloji ve yaratıcılığı aktif kullanan bir yapıya sahip bir şehir olarak tanıtmaktadır. Yazar, şehir kimliğinin şekillenmesi sürecinde köklü değerlerin korunmasının Türk dünyası ile sağlanan ilişkilerin bütünlüğü ile koşullandırılmakta olduğu tespitinden hareketle Türk Dünyası Kültür Başkenti statüsünün Kazan şehrinin kimliğinde, ekonomisinde, turistik potansiyelinde, gündelik yaşamında kalıcı olumlu değişikliklere neden olduğunun altını çizmektedir. Süreçte gerçekleştirilen Mehmet Akif Ersoy ve Gabdulla Tukay'ın çalışmalarının bilimsel temelde irdelenmesi, Türk dünyası tiyatro kültürünün geleneksel yapısının modern dramaturji ile olan tamamlayıcılığının eğitim ve seminerlerle desteklenmesi, heykel sanatının tarihî gerçekliği canlandırma kapasitesinin ölçümü, Tatar folklorunun otantik doğasının tanıtımı, Türk dünyasında İslam geleneklerinin ve Türk-Slav simbiyozunun araştırılması, Müslüman sinemasının öznelliğinin tespiti, Türk halklarında deri işleme sanatının uygulamalı dersleri, ortak yaşam bilincinin tarihî kanıtlarının sunumu

8 Mehmet Topal, “2013 Yılı Türk Dünyası Kültür Başkenti: Eskişehir”, Türk Dünyası Kültür Başkentleri içinde, (Ankara: Nobel Yayınları, 2020), 127-174.

9 Guzel Sadykova, “2014 Yılı Türk Dünyası Kültür Başkenti Kazan”, Türk Dünyası Kültür Başkentleri içinde, (Ankara: Nobel Yayınları, 2020), 175-214. 
ve müzik çeşitliliğinin analizi gibi faaliyetlerin Kazan’ın inovatif yapısını geliştirdiğine, şehrin markalaşmasına zemin sağladığına işaret edilmektedir.

Türk dünyasının dördüncü Kültür Başkenti olan Türkmenistan'ın kadim şehri Merv, 2015 Yılı Türk Dünyası Kültürr Başkenti: Merv $^{10}$ başlığı ile Soner Sağlam ve Berdi Sarıyev tarafından ele alınmıştır. Merv’in tarihsel derinliği, coğrafi konumu, kültürel dokusu, siyasi ve iktisadi yapısının Türk Dünyası Kültür Başkentliği süreci için önemli firsatlar ve imkânlar içerdiğine vurgu yapan yazarlar, şehrin Türk soylu halklar arasında oldukça derin ve güçlü bağların bulunduğunu hatırlatan önemli bir hafıza mekân olduğuna işaret etmektedirler. Bu çerçevede, Sağlam ve Sarıyev özellikle Moğol istilasına kadar olan dönemde ticaretin, kültürel etkinliklerin, bilim, sanat ve edebiyatın en önemli merkezlerinden biri olan Merv'i Türk Dünyası Kültür Başkentliğini her anlamda taşıyabilecek bir şehir olarak tanıtmaktadırlar. İpekyolu'nun güzergâhında bulunan kentin Kültür Başkenti unvanı alması ve bu bağlamda yapılan etkinliklerin şehrin tarihî ve kültürel zenginliği ile Türkmenistan'ın güzelliklerinin tüm dünyaya tanıtılmasına katkı sağladığını vurgulayan yazarlar, Merv’in ipek yolu kavşağında bulunması nedeniyle tarih boyunca pek çok kavmin buluşma noktası ve hoşgörü ve barışın merkezi olmasının etkisiyle süreçte öne çıkan temanın hoşgörü olduğuna işaret etmektedirler.

Türk Dünyası Kültür Başkenti unvanını Merv’den devralan Şeki 2016 yılı Türk Dünyası Kültür Başkenti olarak seçilmiştir. 2016 Yılı Türk Dünyası Kültür Başkenti: Şeki ${ }^{11}$ başlıklı bölümü kaleme alan Elşan İzzetgil, Şeki’nin tıpkı Merv gibi tarihî İpek Yolu üzerinde bulunduğuna, kervanların uğrak yeri olduğuna işaret etmektedir. Yazar, önemli veriler sunan toplumsal ve ekonomik göstergeler bağlamında Şeki'nin Kültür Başkenti seçilmeden önce ve sonrasına ilişkin analizlerde bulunmaktadır. İzzetgil'in söz konusu analizlerden ulaştı̆̆ sonuç ise Kültür Başkenti projesinin Şeki’ye sosyo-ekonomik anlamda olumlu etkilerinin olduğu fakat projenin hedeflerinin yalnızca toplumsal ve ekonomik göstergelerdeki olumlu değişimle sınırlı olmayıp, Türk dünyasının birlik beraberliğini artırmak, değerlerin paylaşımını sağlamak, kültürel mirasın, tarihin ve geleneklerin yaşatılmasına hizmet etmek, ortak bilincin gelişmesini sağlamak başta olmak üzere birçok konuda ilerleme kaydetmek ve sonuç almak gibi önceliklerin yerine getirilmesinde başarılı bir performansın sergilendiği yönündedir. Yazar Şeki'nin Türk Dünyası Kültür Başkenti olması sonucunda UNESCO gibi uluslararası kuruluşlar ile birlikte hareket etme reflekslerinin ortaya çıktığını ve bu durumun 2019 yılında ‘Şeki kentinin tarihî mahallesi ve Şeki Han Sarayı'nın Dünya mirası listesine alınmasına neden olduğunu belirtmektedir.

2017 Yılı Türk Dünyası Kültür Başkenti: Türkistan ${ }^{12}$ başlıklı bölümün yazarı Kanat Ydyrys, Kazakistan'ın Türkistan şehrinin günümüzde Türk dili konuşan halklar için Türk

10 Soner Sağlam ve Berdi Sarıyev, “, 2015 Yılı Türk Dünyası Kültür Başkenti: Merv”, Türk Dünyası Kültür Başkentleri içinde, (Ankara: Nobel Yayınları, 2020), 215-248.

11 Elşan İzzetgil, “2016 Yılı Türk Dünyası Kültür Başkenti: Şeki”, Türk Dünyası Kültür Başkentleri içindei, (Ankara: Nobel Yayınları, 2020), 249-290.

12 Kanat Ydyrys, “2017 Yılı Türk Dünyası Kültür Başkenti: Türkistan”, Türk Dünyası Kültür Başkentleri içinde, (Ankara: Nobel Yayınları, 2020), 291-344. 
dünyasının manevi başkenti olarak kabul edildiğini ve Türkistan’ın Türk Dünyası Kültür Başkenti olması konusunda en önemli tarihsel derinliğin Hoca Ahmet Yesevi'nin hayatında ve fikirlerinde yer aldığını belirtmektedir. Bu çerçevede Büyük mutasavvıf Hoca Ahmet Yesevi ve hocası Arslan Bab'ın türbelerinin Türkistan'da bulunması nedeniyle yazar, Türkistan şehrinin Kazakistan ve Orta Asya'nın kutsal mekânlarından sayıldığına işaret etmektedir. Kültür Başkenti kapsamında gerçekleştirilen faaliyetleri kapsamlı bir biçimde ele alan Ydyrys, çeşitli sanatsal festivaller ile kültürel ve bilimsel etkinliklere ev sahipliği yapan Türkistan'ın Türk dünyasının manevi başkentliği konumunu daha da güçlendirmiş olduğunu vurgulamaktadır.

Kastamonu, 2013 yılında Türk Dünyası Kültür Başkenti seçilmiştir. Eskişehir'den sonra bu unvana Türkiye'den layık görülen ikinci şehir Kastamonu olmuştur. Aynı zamanda tanıtmakta olduğumuz eserin editörlerinden olan ve 2018 Yılı Türk Dünyası Kültür Başkenti: Kastamonu ${ }^{13}$ bölümünün yazarı Fırat Yaldız, Eskişehir'den önce de İstanbul'un 2010 yılı Avrupa Kültür Başkenti olmasının, Türkiye'nin hem Avrupa'da hem de Türk dünyasında Kültür Başkenti çıkarabilecek coğrafi ve kültürel zenginliği göstermesi açısından önemli olduğuna işaret etmektedir. 2018 yılında gerçekleştirilen maddeler hâlinde sıralanamayacak kadar çok etkinliği Kastamonu'nun yerel değerlerini canlandırmak amacıyla yapılan ve devletten ile kamuoyundan ilgi ve destek gören çalışmalar ve Kastamonu ile Türk Dünyası arasında bağ kurulmasına katkı sunan çalışmalar olarak iki başlık altında sınıflandıran Yaldız, bu çalışmalara ilişkin ayrıntılı bilgiler sunmaktadır. 2018 yılında yapılan etkinliklerin Kastamonu'nun Türk dünyasında temsil edilmesi ve tanıtılmasından daha çok Türk dünyasının ve kültürel değerlerinin Kastamonu'da tanıtılması şeklinde gerçekleştiğini vurgulamaktadır. Bu bağlamda Kültür Başkentlerini inceleyen diğer yazarlardan farklı bir biçimde sürecin eksiklik ve aksaklıklarına da değinen Yaldız, Kastamonu'nun Türk Dünyası Kültür Başkenti olduğu 2018 yılındaki faaliyetleri için bir ana tema seçilmemiş, süreci sahiplenerek başarılı şekilde yürütecek bir ajansın kurulmamış, herhangi bir yasal düzenlemenin yapılmamış, kalıcı bir eserin bırakılmamış, faaliyetlerin duyurulacağı ve takip edileceği sosyal medya kanallarının yeterince iyi işlememiş olması gibi nedenlerle Kastamonu'nun Türk Dünyası Kültür Başkentliği sürecinin yasal, kurumsal, finansal açıdan belirsiz geçtiğine ilişkin yorumunu örneklerle somutlaştırmaktadır.

Kırgızistan'ın Bişkek’ten sonraki ikinci büyük kenti olan Oş şehrini 2019 Türk Dünyası Kültür Başkenti: Oş ${ }^{14}$ başlıklı bölümde kaleme alan Zuhra Amerakulovna Altımışova ve Raziyahan Abdiyeva, kentin sadece Kırgızistan'ın değil, Orta Asya'nın en eski yerleşim yerlerinden biri olduğuna işaret etmektedirler. Yazarlar Oş’un demografik yapısı, sanayi, tarım, inşaat, taşımacılık, iletişim, ihracat ve ithalat gibi sektörler üzerinden ayrıntılı ekonomik

13 Fırat Yaldız, "2018 Y1lı Türk Dünyası Kültür Başkenti: Kastamonu”, Türk Dünyası Kültür Başkentleri içinde, (Ankara: Nobel Yayınları, 2020), 345-392.

14 Zuhra Amerakulovna Altımışova ve Raziyahan Abdiyeva, "2019 Yılı Türk Dünyası Kültür Başkenti: Oş”, Türk Dünyası Kültür Başkentleri içinde, (Ankara: Nobel Yayınları, 2020), 393-436. 
durum verilerini okuyucuya sunarak Oş şehrinin Kırgızistan'ın siyasi, dari, ekonomik, bilim ve kültür merkezi olması ve çok uluslu halkları bir arada barındırması gibi nedenlerden dolayı “Türk Dünyası 2019 Kültür Başkenti” seçilmesini olumlu yönde etkilediği yorumunda bulunmaktadırlar. Kültür Başkentliği sürecinde gerçekleştirilen faaliyetleri kültürel, ekonomik, akademik, sportif etkinlikler alt başlıklarında tanıtan Altımışova ve Abdiyeva, Türk Dünyası Kültür Başkentliği kapsamında gerçekleştirilen faaliyetlerin, kentte yaşayan vatandaşların farklılıklarından daha çok benzerliklerinin, kültürlerinin ve dünyalarının ortak olduğunun farkındalığına varmalarına yardımcı olduğunu, günümüzdeki ortak kent kimliğinin ve aynı zamanda Türk dünyası kimliğinin, ortak şuurun ve kardeşlik sevgisinin oluşmasına olanak sağladığını ifade etmektedirler.

Son olarak, 2020 Yılı Türk Dünyası Kültür Başkenti: Hive ${ }^{15}$ bölümünün yazarı Ayşe Çolpan Yaldız, eserin yazıldığı dönemde Türk Dünyası Kültür Başkentliği süreci faaliyetlerine henüz başlanmamış olduğunu belirterek Hive şehrinin, eserde ele alınan kentlerde yaşanan Türk Dünyası Kültür Başkentliği süreçlerinin olumlu ve olumsuz yönleri göz önünde bulundurularak yaşanan deneyimlerden çıkartılacak önemli dersler kapsamında başarılı bir Türk Dünyası Kültür Başkentliği süreci geçirebilmesi amacıyla kaleme alındığının altını çizmektedir. Bu çerçevede yazar, daha önceki Türk Dünyası Kültür Başkentlerinde yaşanan deneyimlerin, süreci başarılı geçirmek için doğal, kültürel ve tarihî mirasların en temel ögeler olmasına rağmen yeterli olmadığını, etkin organizasyon ve kurumsal yapı, planlı faaliyet takvimi, kurumsal eş güdümü, gerekli bütçe, ilan ve reklam stratejisi, aktivitelerin ve faaliyetlerin geniş bir yelpazeyi kapsaması, Türk dünyası kimliğinin kültürel ögeleri için şehrin önemini vurgulayacak faaliyetler, merkezî yönetim ve yerel yönetim arasındaki eş güdüm, merkezî yönetimin ilgisi, uluslararası iş birliği gibi birçok noktanın başarılı bir süreç için önemli unsurlar olduğunu vurgulamaktadır. Başarının ölçütünü ise Yaldız, genel olarak turist sayısındaki artış gibi teknik noktalardan çok, sürecin kente ve ortak bölgesel kimliğe dair kalıcı unsurlar bırakıp bırakmadığı olarak tespit etmektedir.

Kitabın Sonuç ${ }^{16}$ bölümünü kaleme alan Timur Kocaoğlu, Türk dünyasının farklı coğrafyalarını, siyasi ve toplumsal tarihinin kilometre taşlarını izleyerek ve şahsi tecrübelerinden de örnekler sunarak "Türk Dünyası" terimine ve Türk dili ve alfabesine ilişkin oldukça detaylı bir tartışma ortaya koymaktadır. Ayrıca Kocaoğlu, Kültür Başkentliği süreçlerinde yaşanan eksikliklere okuyucunun dikkatini çekerek, süreçte ortaya çıkan en belirgin eksikliği bir sonraki şehirde yürütülen Kültür Başkenti etkinliklerinde daha önceki şehirlerin Kültür Başkentliği sürecindeki deneyimlerinden yararlanılmamış olması şeklinde görmekte ve bu durumun kaynağını, Türk Dünyası Kültür Başkentleri arasındaki eş güdüm eksikliği olarak tespit etmektedir.

15 Ayşe Çopan Yaldız, “2020 Yılı Türk Dünyası Kültür Başkenti: Hive”, Türk Dünyası Kültür Başkentleri içinde, (Ankara: Nobel Yayınlar1, 2020), 437-484.

16 Timur Kocaoğlu, Türk Dünyası Kültür Başkentleri adlı kitabına Sonuç, (Ankara: Nobel Yayınları, 2020), 435494. 
Türkçede pek çok açıdan ilk olma özelliğini taşıyan eser, "Türk Dünyası Kültür Başkentleri” uygulamasının kavramsal, kuramsal ve kurumsal arka planı, Kültür Başkenti seçilen kentlerin her birinde süreç kapsamında gerçekleştirilen faaliyetlerin kente, Türk dünyasında kültürel iş birliğine ve ortak kültürel kimliğe ilişkin katkılarını ortaya koymaktadır. Günümüze kadar Türk Dünyası Kültür Başkenti olarak seçilen kentlerin çeşitli açılardan ele alındığı bu çalışma, önümüzdeki yıllarda seçilecek Türk Dünyası Kültür Başkentleri ve sürecin tüm aktörleri için bir kılavuz, konuya disiplinlerarası bir perspektifle yaklaşan farklı disiplinlerden akademisyenler için başvuru kaynağı olarak değerlendirilmeyi beklemektedir.

\section{Kaynak}

Yaldız, Fırat (Ed.). Türk Dünyası Kültür Başkentleri. Ankara: Nobel Yayınları, 2020. 